\title{
Aplicação do modelo Sustainability Assessment for Agriculture Cooperatives (SAAC) para avaliação do desempenho de sustentabilidade das operações de cooperativas agropecuárias no município de Ituiutaba/MG.
}

\author{
Applying the Sustainability Assessment for Agriculture Cooperatives (SAAC) model \\ to evaluate the sustainability performance of agricultural cooperative operations in \\ the municipality of Ituiutaba / MG.
}

\begin{abstract}
Resumo
O presente estudo objetivou avaliar a sustentabilidade nas operações de cooperativas agropecuárias no município de Ituiutaba em Minas Gerais com a aplicação do modelo de Sustainability Assessment for Agriculture Cooperatives (SAAC). A pesquisa é de cunho qualitativo e utilizou dados coletados a partir de documentos e entrevistas semiestruturadas com gestores de cooperativas agropecuárias no município. Os principais achados revelaram que as cooperativas agropecuárias de Ituiutaba/MG ainda precisam de esforços visando à sustentabilidade das operações de produção. Os resultados mostraram a) a não existência efetiva da consciência ambiental disseminada, b) a deficiência de projetos sociais que atendem a comunidade, c) baixo reuso da água e incipiente uso de energias renováveis, e por fim d) a fraca educação cooperativista. Infere-se que o estágio atual da incorporação das práticas de sustentabilidade nas operações das cooperativas no município foi visto, como incipiente.
\end{abstract}

Palavras-chave: modelo sustainability assessment for agriculture cooperatives (saac), cooperativas agropecuárias, ituiutaba/mg.

\begin{abstract}
The objective of this study was to evaluate the sustainability of agricultural cooperative operations in the municipality of Ituiutaba in Minas Gerais, Brazil, using the Sustainability Assessment for Agriculture Cooperatives (SAAC) model. The research is qualitative and used data collected from documents and semistructured interviews with managers of agricultural cooperatives in the municipality. The main findings revealed that the agricultural cooperatives of Ituiutaba / MG still need efforts aimed at the sustainability of their production operations. The results showed a) the non-existence of disseminated environmental awareness, b) the lack of social projects that serve the community, c) the low reuse of water and the incipient use of renewable energies, and d) the weak cooperative education. It is concluded, therefore, that the current stage of the incorporation of sustainability practices into cooperative operations in the municipality was seen as incipient.
\end{abstract}

Keywords: model sustainability assessment for agriculture cooperatives (saac), agricultural cooperatives, ituiutaba / mg.

Debora Barros Nicolau ${ }^{\text {I }}$, Edson Arlindo Silva ${ }^{\text {II }}$, Juliene Barbosa Ferreira ${ }^{\text {III }}$, Victor Manuel Barbosa Vicente ${ }^{\text {IV }}$

Universidade Federal de Uberlândia (UFU), Uberlândia, MG. deborah.nicolau@hotmail.com

Universidade Federal de Uberlândia (UFU), Uberlândia, MG. edsonasilva@ufu.br

Universidade Federal de Uberlândia (UFU), Uberlândia, MG. juliene.ferreira@ufu.br

Universidade Federal de Uberlândia (UFU), Uberlândia, MG. victorvicente.unb@gmail.com 


\section{Introdução}

Numa economia de mercado, as empresas do setor privado detêm a maior parcela dos meios de produção, sendo o lucro o principal objetivo do modelo econômico capitalista. No entanto, essa maximização desenfreada e infinita do lucro endossa um modelo de desenvolvimento altamente entrópico e predador que tem sido fortemente criticado por autores, que entendem que a competitividade de uma empresa depende de vários fatores que vão muito além de lucro. É necessário ter lucro, mas sem prejudicar aquele que está ao redor. Portanto, adequar as atividades da empresa ao conceito de desenvolvimento sustentável é uma questão de sobrevivência e de competitividade (TINOCO; ROBLES, 2007; AKTOUF, 2004; FERREIRA, 2003). Assim, a preservação e a sustentabilidade do meio ambiente têm-se tornado cada vez mais foco de preocupação da sociedade, sendo um importante fator para o crescimento dos negócios e dos empreendimentos, forçando regulamentações como formas de deter e de mitigar a degradação ecológica do uso consciente dos recursos naturais na geração de riqueza e renda pelos mais variados negócios. Haja vista que a sustentabilidade é a capacidade de crescimento econômico contínuo com a distribuição adequada das riquezas sociais e com a proteção ecológica (BORGES, ZOUAIN, 2010). A busca constante da utilização de tecnologias alternativas possibilita a redução dos impactos socioambientais ocasionados por algumas atividades econômicas, dado que um dos princípios do cooperativismo é produzir bens e serviços alavancados no tripé da sustentabilidade, ou seja, é oferecer produtos e serviços, economicamente viáveis, socialmente justos e ambientalmente corretos (FRANTZ, 2003). Nesse sentido, o surgimento das cooperativas foi a união de pessoas voluntárias em prol de obterem benefícios econômicos e sociais, considerando-se que as cooperativas além de contribuírem com os cooperados, proporciona oferta emprego, renda, fornece suporte às ações sociais na comunidade em que elas estão inseridas (ABARGHANI, SGOBEIRI, MEIBOUDI, 2013).

Dados da Organização das Cooperativas Brasileiras OCB (2016) apontam que as cooperativas agropecuárias são as mais representativas do país, pois contemplam cerca de $50 \%$ das cooperativas ativas, sendo a que gera mais empregos diretos, contribuem com $38,4 \%$ do PIB agropecuário e geram US $\$$ bilhões de exportações diretas. A produção agropecuária de Ituiutaba destaca-se por contribuir economicamente com parte da produção mineira e nacional de grãos e leite e seus derivados (SOUTO; BEZZI, 2017), porém mesmo com significativos ganhos econômicos, a atividade agropecuária no município requer uma atenção considerável quanto aos impactos gerados tanto no meio ambiente, quanto nos aspectos sociais.

Partindo deste ponto de vista e das discussões acerca dos modelos de avaliação de sustentabilidade, dentre as quais a Avaliação da Eficiência Econômico-Financeira de Cooperativas (OLIVEIRA, 1996), o Sistema Contábil Gerencial Ambiental (SIGOGEA), (DOMÊNICO et al. 2015; DAVIES, 2017) o Balanced Scorecard nas cooperativas (PORTO, 2002), Sistema de mensuração de sustentabilidade (DELAI; TAKAHASHI, 2011), fica evidente que as organizações cooperativistas, em geral, e as cooperativas agropecuárias em particular devem garantir além da eficiência financeira à eficiência socioambiental. Assim, nasce a necessidade de estratégias adequadas para gerir o crescimento e a sobrevivência destas cooperativas em um mercado cada vez mais competitivo, tendo em vista que um dos princípios se embasa no interesse pela comunidade, isto é, as cooperativas trabalham para o desenvolvimento sustentável de suas comunidades por meio de políticas aprovadas por seus associados. Sendo assim, é imprescindível uma análise das estratégias e da gestão de forma diferente das organizações empresariais tradicionais. (MARCIS, 2017).

Pesquisas revelam que a avaliação de desempenho sustentável das operações de cooperativas agropecuárias é fonte para elaboração e desenvolvimento de políticas sobre desenvolvimento sustentável e podem melhorar consideravelmente a gestão estratégica (MACRIS, 2017; CÂNDIDO, 2016), contribuindo para que estas organizações se tornem ágeis, adaptáveis e alinhadas (KLEINDORFER; SINGHAL; WASSENHOVE, 2005). 
Para fins desta pesquisa, selecionou-se o modelo de avaliação da sustentabilidade das cooperativas agropecuárias ou Sustainability Assessment for Agriculture Cooperatives (SAAC) proposta por Marcis (2017). O modelo escolhido foi adaptado ao estudo em tela, com inclusão de dados complementares para a análise. Segundo a proponente, o modelo se mostrou factível, de relativo fácil uso e útil e pode ser a base de avaliação de desempenho sustentável das operações de cooperativas agropecuárias melhorando, dessa forma, a gestão estratégica. (MARCIS, 2017, p.8).

Assim, os benefícios que esse tipo de avaliação pode trazer para as cooperativas em seus processos internos e diante de seus concorrentes e da comunidade, serão importantes para o desenvolvimento e para o crescimento organizacional das cooperativas, pois muitas ainda possuem fragilidades e desafios a serem superados no quesito sustentabilidade socioambientais (SILVA, 2014).

Tendo em vista o exposto, o presente estudo visa responder à seguinte pergunta de pesquisa: Será que as práticas de sustentabilidade estão incorporadas nas operações de cooperativas agropecuárias no município de Ituiutaba? Elas estão adequadas e atendem aos indicadores do modelo Sustainability Assessment for Agriculture Cooperatives (SAAC).

Dado ao contexto e à pergunta anteriormente apresentados, o presente estudo tem como objetivo geral avaliar a sustentabilidade nas operações de cooperativas agropecuárias no município de Ituiutaba em Minas Gerais, a partir da aplicação do modelo de avaliação de sustentabilidade denominado Sustainability Assessment for Agriculture Cooperatives (SAAC), modelo de avaliação do desempenho da sustentabilidade de operações de cooperativas agropecuárias, proposta, testada e validada por Marcis (2017).

Este artigo foi estruturado da seguinte forma: a introdução apresentada na primeira seção; na segunda, será apresentada a revisão da literatura referente ao tema; na terceira, são descritos os procedimentos metodológicos empregados na elaboração deste artigo; já na quarta, serão descritos os resultados obtidos nesta pesquisa e, na quinta seção, apresenta-se a conclusão do estudo.

\section{Revisão de literatura}

Nesta revisão de literatura, trataram-se os seguintes temas: Reflexões sobre conceitos de cooperativismo, autogestão e educação cooperativista; cooperativas agropecuárias; avaliação de desempenho das cooperativas: conceitos, modelos e desafios e o modelo SAAC de avaliação de desempenho das cooperativas agropecuárias.

\subsection{Reflexões sobre conceitos de cooperativismo, autogestão e educação cooperativista}

As origens do cooperativismo no mundo destacam como os principais precursores: Conde de Saint-Simon; Robert Owen; Charles Fourier; Philippe Buchez; Jean Joseph Charles Louis Blanc, Willian King e muitos outros predecessores do Ideário Cooperativista. Estas ideias, foram sempre inspiradas na altruística ambição de obter melhores condições gerais de vida a fim de posteriormente sensibilizar sobremaneira as ideias da cooperação como instrumento para enfrentar a crise econômica e a fonte geradora de emprego e de renda (BENATO, 1994; KLAES, 2005; SALES, 2010).

Dessa forma, nos meados do Século XIX, reagindo às condições inadequadas de sobrevivência, os trabalhadores lançaram as primeiras sementes do cooperativismo moderno na Inglaterra - Cooperativa dos Probos Pioneiros de Rochdale, 1844. Contemporânea ao movimento Inglês, que atuava no segmento de consumo, surge, na Alemanha a partir de 1850 , a primeira Cooperativa de Crédito, fundada por Schulze-Delitzsch. O cooperativismo de crédito surgiu para 
combater as relações desiguais de troca e no exercício da atividade laboral que penalizavam sobremaneira os trabalhadores rurais e urbanos. Junto à necessidade de se extirpar esse mal, era preciso criar uma ordem mais justa, que priorizasse a obtenção de vantagens comuns nas atividades econômicas e que, principalmente, tivesse como foco central o ser humano (RIOS, 2018; KLAES, 2005).

Nesse âmbito, o cooperativismo surge como alternativa para a geração de renda em um mercado de trabalho no qual as pessoas percebem que sozinhas terão pouca ou nenhuma chance de conseguir qualquer oportunidade. Um empreendimento coletivo sempre tem maior poder de negociação e de sustentação. Outra importante característica da cooperativa é que ela surge como possibilidade de evitar a total precarização do trabalho, o combate às elevadas taxas de desemprego e aos baixos salários recebidos pelos trabalhadores, garantindo assim, alternativas e soluções que se adaptem melhor às condições econômicas e sociais nas atividades de colheita e produção de bens e serviços prestadas pelos trabalhadores (RIOS, 2018).

Elencaram-se, assim, os princípios cooperativistas, que são as linhas orientadoras por meio das quais as cooperativas levam à prática os seus valores. Segundo Rios (2018), são seguintes os princípios norteadores do cooperativismo a) Adesão livre e voluntária dos seus associados; b) Gestão democrática, c) Educação, formação e informação; d) Participação econômica dos seus membros; e) Autonomia e independência com relação ao governo, empresas ou outras organizações, f) interesse pela comunidade e g) Intercooperação entre empreendimentos solidários.

Além disso, há diversas tipologias de cooperativas que foram sendo criadas ao longo do tempo para atender vários setores da economia dos países, dentre eles: trabalho, consumo, crédito, habitacionais, saúde, infraestrutura e agropecuárias (SICOO, 2016).

A classificação dos ramos foi dada pela Organização das Cooperativas Brasileiras (OCB) para facilitar a organização política das cooperativas e possibilitar sua inserção no mercado competitivo (MARRA, 2016). Para Reisdorfer (2014, p.9), o segmento agropecuário é definido como aquele composto por produtores agrícolas e que fornecem insumos agropecuários, constituindo-se como um segmento por cooperativa de qualquer cultura ou criação rural. É o mais conhecido pela sociedade brasileira, uma vez que participa significativamente da organização e do desenvolvimento da agricultura, bem como das exportações, com expressiva representação na balança comercial e, ao mesmo tempo, abastece o mercado interno de produtos alimentícios. Além disso, esse sistema oferece a prestação de vasto leque de serviços, desde assistência técnica, armazenagem, industrialização e comercialização dos produtos, até a assistência social e educacional aos cooperados. Ademais, as cooperativas agropecuárias no Brasil são o segmento economicamente mais forte do cooperativismo (REISDORFER, 2014, p.9).

O próximo segmento a ser definido por Reisdorfer (2014) é o de consumo “[...] as cooperativas de consumo se subdividem em fechadas e abertas. As fechadas são as que admitem como cooperados somente as pessoas ligadas a uma mesma empresa, sindicato ou profissão. As abertas, ou populares, são as que admitem qualquer pessoa que queira a elas se associar".

Já as cooperativas do ramo de crédito são instituições financeiras formadas pela associação de pessoas para prestar serviços financeiros exclusivamente aos associados, tendo em vista que os cooperados são ao mesmo tempo donos e usuários. $\mathrm{O}$ associados têm poder igual de voto independentemente da sua cota de participação no capital social da cooperativa. (BANCO CENTRAL DO BRASIL, 2012).

Marra (2016) mostra o próximo ramo o educacional como sendo de cooperativas "[...] formadas por professores (que se organizam como profissionais autônomos para prestarem serviços educacionais), por alunos de escolas agrícolas (que além de contribuírem para o sustento da escola, produzem mercadorias a serem comercializadas)". 
As cooperativas do segmento especial objetivam a organização e a gestão de serviços sociossanitários, "[...] bem como educativos às pessoas que, de certa forma, precisam ser tuteladas ou que se encontram em necessidade de amparo" (MARRA, 2016, p.17).

Marra (2016, p.14) também define os segmentos de cooperativas do segmento habitacional como aqueles cujo objetivo é a construção e a manutenção de residências para a população e, ainda, abrange consórcios. Já o segmento de mineração é constituído por cooperativas de mineração, em virtude de que a área que mais se destaca é a extração de mineral e essas cooperativas buscam por condições mais humanas nesse trabalho. Por outro lado, o segmento de produção é composto por cooperativas que produzem bens de consumo como móveis, tecidos, eletrodomésticos etc.

Já o segmento de infraestrutura é composto pelas cooperativas de eletrificação rural, mecanização agrícola, limpeza pública e telefonia rural. O próximo segmento a ser definido é o de trabalho constituído por pessoas ligadas a uma determinada ocupação profissional, com a finalidade de melhorar a remuneração e as condições de trabalho de forma autônoma (MARRA, 2016).

Além desses, há o segmento de cooperativas de saúde, segundo Marra (2016), criado no Brasil com o intuito de promover a prestação e a promoção da saúde humana. Já o segmento de transportes objetiva a prestação de serviços de transporte de cargas e passageiros e por último o segmento de turismo e lazer que tem como prioridade atender serviços turísticos, lazer, entretenimento, esportes, artísticos, eventos e de hotelaria.

Ao falar dos segmentos do cooperativismo, entende-se também como essas cooperativas trabalham para gerir estes negócios, assim se depara com a autogestão que possui um modo de agir baseado na coletividade, nas ações que são tomadas de acordo com a experiência, ideias e intenções do grupo, tendo em vista que "a essência dessa prática social está fundada na repartição do poder e do ganho, na união de esforços e no estabelecimento de outro tipo de agir coletivo, que encontra na cooperação qualificada a implementação de outro tipo de ação social” (CARVALHO, 2012, p.50). O diferencial da autogestão é que seus princípios são baseados na democracia, na solidariedade e na igualdade, caracterizando uma sociedade de pessoas (RODRIGUES, 2004, p.38).

Portanto, a autogestão quando relacionada ao cooperativismo é definida como um meio de gestão que visa à democracia em uma sociedade, respeitando as ideias e as sugestões, o lucro não é primordial, mas sim trazer renda para todos os envolvidos de modo que possa crescer e possuir uma vida digna.

Para inserir o conhecimento de autogestão nos negócios, é necessário que gestores que possuem empreendimentos tenham como ideologia o cooperativismo a fim de conhecer e entender a educação cooperativista.

Para isso, a Educação Cooperativista deve colocar à disposição do movimento o instrumental cultural, científico e tecnológico criado pelo mundo moderno, para respeitar o conhecimento e as experiências populares, a fim de obter um aumento significativo dos bens e serviços gerados pela ação da cooperativa (SAFANLLI, 2011. p.5).

Para Schneider (2008, p.10), “[...] A educação doutrinária é fundamental, pois é ela que, por meio dos seus valores e princípios, dá sentido a todo o processo, que incentiva e direciona todas as atividades e práticas cooperativistas em prol de maior bem-estar e dignidade das pessoas que compõem a cooperativa".

Diante das definições, fica claro que a educação cooperativista é importante, pois dela se capacitam os indivíduos a compreender o dinamismo da autogestão nas cooperativas. 


\subsection{As cooperativas agropecuárias}

As cooperativas agropecuárias são formadas por produtos rurais que buscam atender com agilidade o mercado consumidor para negociar compra de insumos e vender rápido produção. Para isso, um dos principais objetivos das cooperativas agropecuárias é dar visibilidade e auxiliar o produtor rural no mercado competitivo (DATACOPER, 2018).

Também Sicoob (2016) explicou que as cooperativas agropecuárias “[...] tem por vocação principal ajudar seus associados a comercializar, da melhor maneira possível suas produções, conseguindo bons compradores e preços para os produtores agropecuários”.

Ainda o jornal Rural News (2017) fala que uma das principais funções das cooperativas agrícolas é conseguir escoar, da melhor maneira possível, a produção agropecuária. Contudo, é possível compreender que o principal intuito das cooperativas agropecuárias é dar suporte aos produtos rurais em questões de vendas e negociação de insumos. Já as cooperativas agropecuárias são importantes, pois conseguem unir os produtos do mesmo seguimento e negociar no mercado em grande escala de produção, além de fechar grandes negócios inclusive exportações que para o produtor individual costuma ser inviável (SICOOB, 2016, p. 3).

Além da parte comercial, a maioria das cooperativas mantém uma equipe de técnicos, veterinários e agrônomos a fim de dar suporte aos produtores, garantindo maiores e melhores produções, o que é interessante tanto do cooperado quanto da cooperativa. Essa assessoria técnica é muito valiosa, principalmente, para quem está iniciando a produção. Se um proprietário rural pretende iniciar uma plantação ou criação, deve sempre procurar a cooperativa mais próxima, filiarse e começar a usufruir das facilidades que essa lhe oferece. As cooperativas também prestam serviços para o produtor, como o beneficiamento de café, pasteurização de leite, embalagem de produtos etc (RURAL NEWS, 2017, p. 22). Portanto, as cooperativas agropecuárias têm por vocação principal ajudar os associados, os produtores rurais a comercializar, da melhor maneira possível suas produções, conseguindo bons compradores e preços para os produtos agropecuários. Com o ganho de escala na produção, os cooperados conseguem fazer grandes negócios, inclusive exportações, que costumam ser inviáveis para o produtor individual. Algumas dessas associações ainda oferecem serviços para o produtor, como o beneficiamento de café, a pasteurização de leite, a embalagem de produtos, além de tecnologias de controle de pragas e de doenças visando à melhoria das pastagens para o incremento da produção e da produtividade de leite e de carnes diversas (CRÚZIO, 1999).

\subsection{Avaliação de desempenho das cooperativas: conceitos, modelos e desafios}

Na literatura sobre as cooperativas, existem vários modelos de negócio, cujo objetivo é a avaliar o desempenho das cooperativas. (RAJA, LARIO E LEMA, 2006).

Visto a importância das sociedades cooperativas principalmente para setor agrícola, Sánchez e Martí (2003) vislumbram a necessidade de definir o desempenho de uma sociedade cooperativa agrícola e estabelecer indicadores para sua mensuração. Assim, surgem vários estudos com intuito de criar um modelo que consiga mensurar adequadamente as empresas de cooperativas agropecuárias.

Oliveira (1996) criou um modelo subdividido em dois, sendo o primeiro a avaliação da eficiência econômico-financeira e o segundo a eficiência político-social. A avaliação da eficiência econômico-financeira visualiza cinco grupos de indicadores que podem ser extraídos de resultados e demonstrativos contábeis. A seguir, na Tabela 1 apresentam-se tais indicadores e suas variáveis:

Porto (2002), em sua pesquisa, elaborou um modelo para as cooperativas a partir do Balanced Scorecard adaptado, em que são analisadas quatro perspectivas: financeira, clientes, processos internos e aprendizado e crescimento. Com isso, cada uma das perspectivas do Balanced Scorecard utiliza ferramentas auxiliares, de modo a compor um modelo que possa ser adaptado e integrado à estratégia competitiva de qualquer cooperativa. 
Está pesquisa revelou que a análise final do projeto verifica que não é possível gerenciar o desempenho futuro, utilizando apenas indicadores financeiros. A implantação do modelo exposto neste trabalho torna-se fundamental para a melhoria contínua na gestão das cooperativas.

Raja, Lario e Lema (2006) destacam as vendas, a participação de mercado, os benefícios e a rentabilidade como indicadores mais apropriados para a questão. Já Gimenez, Del Río e Gomis (200o) elegem, primeiramente, para essa função o valor expresso pelo Ativo Total que reflete o conjunto de capitais empregados no processo produtivo e, em segundo lugar, estão os Custos Totais formados a partir do custo da compra da produção dos sócios somados aos custos de industrialização e aos gastos operacionais.

No trabalho desenvolvido por Ferreira e Braga (2007), utilizaram-se variáveis como (1) faturamento do setor cooperativo estudado em termos monetários, (2) resultado operacional em termos monetários, (3) quantidade de matéria-prima processada em sua unidade de medida, (4) gasto total com empregados expresso em termos monetários, (5) ativo permanente total em termos monetários para representar o capital e o (5) número de fornecedores representando uma parte dos custos de transação. No entanto, é ressaltado por Sánchez e Martí (2003) que uma ampla gama de perspectivas pode ser utilizada para avaliar o referido desempenho. Elas por sua vez podem abranger indicadores, objetivos de caráter financeiro e econômico e medidas de caráter subjetivo ligadas à satisfação dos clientes, proprietários da organização etc. Logo, comentam que a utilização exclusiva de indicadores financeiros pode resultar em uma medida enganosa, já que não se observa se os sócios componentes das associações cooperativas tiveram os objetivos realizados.

Apesar de todos os modelos citados anteriormente serem de suma importância para avaliar a maturidade econômico-financeira das cooperativas, o interesse neste estudo recairá, sobre o modelo de avaliação de sustentabilidade das operações das cooperativas agropecuárias, que será apresentada a seguir.

\subsubsection{O modelo SAAC de avaliação de desempenho das cooperativas agropecuárias}

O Modelo denominado Sustainability Assessment for Agriculture Cooperatives (SAAC) é apresentado em cinco dimensões: 1- econômico com oito indicadores; 2- ambiental com vinte e sete indicadores; 3- social com dezesseis indicadores; 4- específicos de cooperativas com dezenove indicadores e as 5- relações comerciais com oito indicadores, totalizando setenta e oito indicadores que medem o desempenho de sustentabilidade das cooperativas agropecuárias (MARCIS, 2017).

Figura 1 - Modelo SAAC

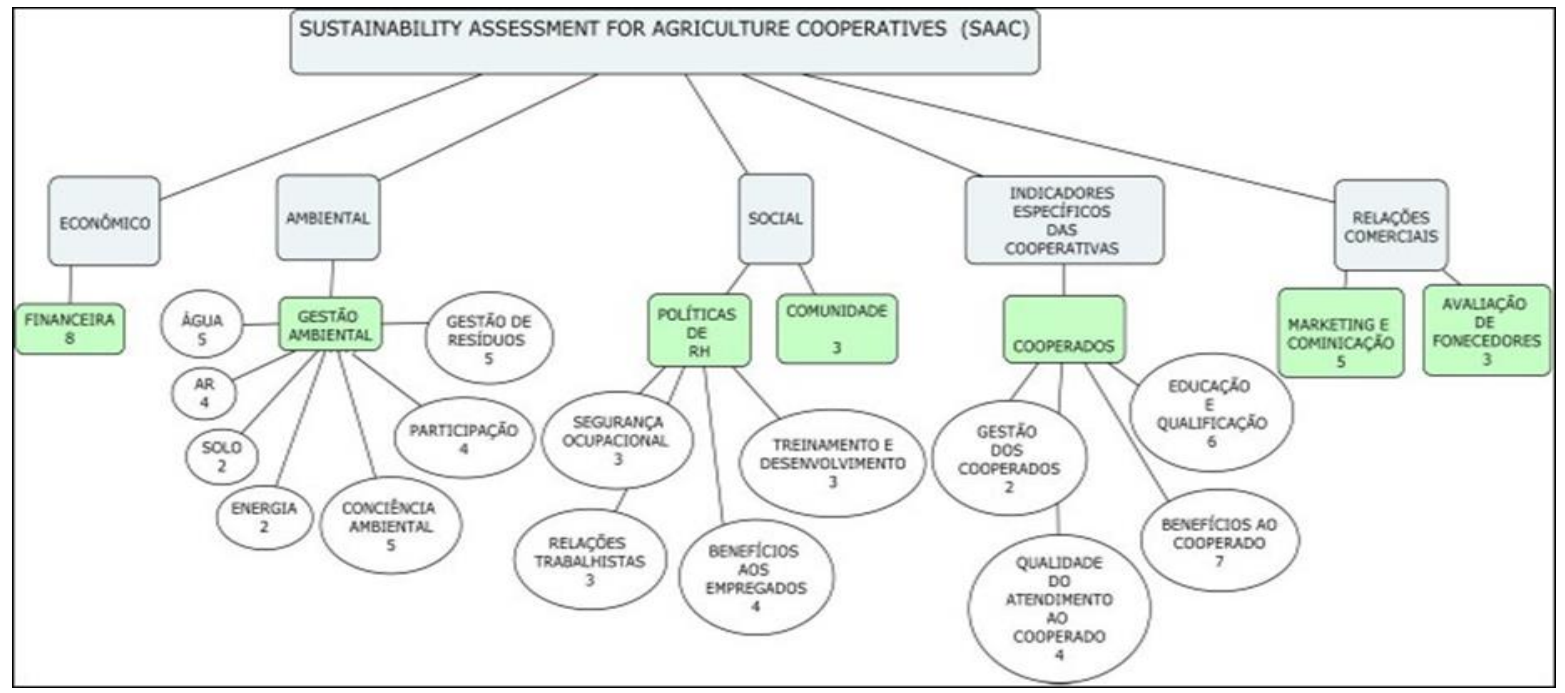

Autor: Marcis, 2017, p.46. 
Como se observa pela imagem, o modelo é desmembrado a partir dos cinco indicadores principais, sendo composto por subcategorias para um melhor entendimento do que cada indicador principal, buscando analisar em profundidade as categorias de estratégias nas cooperativas agropecuárias.

$\mathrm{Na}$ dimensão1- econômico seguido por sua subcategoria financeira evidencia-se que se buscam os resultados financeiros das ações das cooperativas; no indicador 2-ambiental, subcategoria Gestão Ambiental, desmitificado em mais sete categorias busca compreender e encontrar a participação, certificações e ações que as cooperativas desenvolvem nesta temática; já o indicador 3social, seguido pela subcategoria Políticas de RH, neste tópico o modelo busca entender a relação dos trabalhadores dentro das cooperativas. No indicador 4- específico das cooperativas e de seus subindicadores demonstram querer entender os serviços oferecidos para os cooperados e no indicador 5- relações comerciais, subdividido em duas categorias marketing e comunicação e avaliação de fornecedores, neste tópico estuda-se a relação externa da cooperativa, a relação da mesma com stallholders.

Para compreender o modelo, cada dimensão buscava informações dentro das cooperativas como o econômico definido pela categoria financeira que retirava informações conforme o retorno sobre o ativo (ROA), retorno sobre o investimento (ROI), retorno sobre o patrimônio líquido (ROE), fluxo de caixa, endividamento dentre outras informações financeiras para compreender a situação da cooperativa e analisar como o modelo de negócio está se portando diante do mercado, visto que um dos objetivos das cooperativas é a capacidade econômica contínua de crescimento e distribuição adequada de riquezas sociais (BORGES; ZOUAIN, 2010).

No mesmo modelo, há a dimensão Ambiental, classificada como categoria gestão ambiental, é analisado a partir de 27 indicadores, ainda divido por subcategorias como água que busca obter dados como investimentos em proteção ou da preservação dela, reutilização da água da chuva e do seu consumo na cooperativa. Outra subcategoria é o ar no qual o modelo investiga o investimento em reflorestamento, tratamento em emissões de poluentes na atmosfera, existência de veículos biocombustíveis e idade média da frota de carros. A próxima subcategoria é o solo que visa se as cooperativas possuem a disponibilidade de coleta de embalagens tóxicas vazias e os cooperados que participam de campanhas ambientais sobre o uso de agroquímicos. A subcategoria energia averigua se a cooperativa utiliza energia renovável e se existe redução de consumo em energia nos últimos meses. A próxima é a consciência ambiental, nesta subcategoria, buscam-se informações como certificações ambientais, autuações e os níveis das multas ambientais. Na subsequente subcategoria, identificam-se as participações das cooperativas em reuniões e conferencias sobre o desenvolvimento sustentável e sobre a responsabilidade social, assim como as premiações ou os projetos de sustentabilidade e a última subcategoria gestão de resíduos tem interesse em saber se há uma preocupação em relação à redução de materiais na produção, copos plásticos e impressões, bem como se as cooperativas reutilizam materiais e ou reciclam.

A próxima dimensão citada no modelo de MARCIS (2014) é a Social, sendo a categoria de políticas de $\mathrm{RH}$, que também divide-se em subcategorias a primeira é segurança ocupacional a qual busca informação nas cooperativas como certificações de boas práticas de higiene segurança e saúde no trabalho das cooperativas, ouvem-se acidentes com afastamento e investimentos em segurança e medicina do trabalho. A próxima subcategoria são as relações trabalhistas que identificam as ações trabalhistas, índice de rotatividade de pessoal e se existe pesquisa de satisfação dos empregados. Outra subcategoria do modelo são os benefícios aos empregados que apontam os incentivos, os prêmios, a assistência médica, o plano de previdência privada e a seguro de vida a eles. A próxima subcategoria é o treinamento e o desenvolvimento que analisa se a cooperativa investe na educação de seus empregados e se os empregados participam de cursos de capacitação. Finalmente, a última subcategoria é a comunidade, em que se quer saber sobre os investimentos em projetos sociais, culturais e esportivos na comunidade. 
A quarta dimensão classificada como indicadores específicos das cooperativas, seguido pela categoria cooperados, sendo a primeira subcategoria gestão de cooperados, que busca informações sobre a quantidade de cooperados que entraram e saíram nos últimos dois exercícios. A próxima subcategoria é a qualidade do atendimento ao cooperado que identifica reclamações solucionadas nos dois últimos exercícios, visitas técnicas realizadas pela cooperativa, benefícios ofertados pela cooperativa para os cooperados e o reconhecimento da cooperativa para com eles. A última subcategoria é educação e a qualificação, o modelo neste tópico quer identificar o investimento em educação, treinamento e cursos superiores, participação em palestras de educação financeira e planejamento familiar rural.

A última dimensão levantada no modelo é a respeito das relações comerciais, divide-se em marketing e comunicação, investiga informações como porcentagem que a cooperativa apresenta no mercado em relação ao produto principal, quanto é investido em comunicação em marketing, certificações de qualidade do produto e pesquisa de satisfação. O segundo tópico é avaliação de fornecedores busca se a cooperativa se preocupa com as avaliações de seus fornecedores tais como ambientais, de qualidade e solidariedade.

O modelo SAAC foi criado com o intuito de auxiliar a estruturação das estratégias de gestão, tomada de decisão e no desenvolvimento da sustentabilidade dos cooperados agropecuários. Os indicadores utilizados no modelo Sustainability Assessment for Agriculture Cooperatives verificam se a prática vivenciada pelas cooperativas condiz com o modelo.

\section{Metodologia}

\subsection{Caracterização da pesquisa}

Este estudo é descritivo e de cunho qualitativo, realizado sob a forma de estudo de múltiplos casos, que selecionou as seguintes Cooperativas Agropecuárias: As Cooperativas Agropecuárias A, B, C, D e E com suas sedes localizados na zona urbana e não rural da região de Ituiutaba, no estado de Minas Gerais.

A pesquisa foi desenvolvida conforme as seguintes etapas, com a utilização dos métodos e técnicas que serão descritas a seguir:

1) bibliográfica: revisão da literatura em livros, periódicos, dissertações de mestrado e teses de doutorado, anais de congressos científicos e outras publicações convenientes para subsidiar a teoria e a análise dos dados.

2) campo: coleta de dados primários por meio de entrevistas semiestruturadas com gestores e associados das cooperativas agropecuárias encontradas no município de ItuiutabaMG. Utilizaram-se roteiros de entrevistas semiestruturadas para um único respondente por vez - entrevistas "em profundidade". As entrevistas foram gravadas e depois transcritas em Word texto.

As entrevistas foram realizadas de ago/set de 2018. Após as transcrições, os textos foram submetidos à técnica de análise de Conteúdo, buscando identificar a relação e a percepção das respostas de acordo com o modelo proposto no estudo a fim de evidenciar a importância de estratégias de sustentabilidade em cooperativas agropecuárias. A análise e o tratamento dos dados das entrevistas foram feitos mediante software para análise qualitativa de dados o IRAMUTEC. 


\subsection{Modelo de análise}

O Sustainability Assessment For Agriculture Cooperatives (SAAC) foi selecionado para os fins deste trabalho por ser uma ferramenta já testada e validada e por apresentar uma arquitetura aberta, possibilitando a escolha dos indicadores que serão utilizados e não há um número fixo para a quantidade destes. A etapa da formatação do modelo é considerada uma das mais importantes no âmbito dos moldes de avaliação de sustentabilidade, pois é momento da escolha das dimensões e indicadores que, neste caso, se realizou a partir do trabalho desenvolvido por Marcis (2017).

A seguir, apresenta-se o detalhamento correspondente a cada dimensão, suas categorias, o foco de análise e as respectivas subcategorias do Modelo de Análise.

O modelo de avaliação de desempenho em sustentabilidade das operações de cooperativas agropecuárias construído para esta pesquisa engloba a avaliação de três dimensões principais: a) ambiental, b) social e c) relações comerciais.

A Dimensão I "Ambiental" compreende de um modo geral os condicionantes da gestão ambiental que avaliam se nas cooperativas pesquisadas existem ou não práticas e/ou métodos para o uso racional e sustentável dos recursos naturais; da preservação da biodiversidade; do uso dos métodos corretos de descarte de lixo e dos materiais tóxicos; adoção de sistemas de reciclagem; uso de métodos que reduzam a poluição do ar, da água e do solo; de tratamento e reutilização dos recursos naturais e de matéria-prima no processo produtivo das cooperativas e finalmente das práticas de redução do consumo de água e energia nas mesmas ações, participações e certificações das cooperativas em temas relacionados ao ambiente sustentável.

Portanto, a categoria Gestão Ambiental e suportado por outras quatro subcategorias. A primeira Subcategoria - Água busca a) analisar a existência de investimentos em proteção e preservação de fontes de água; b) analisar a existência de investimentos em reuso de água e c) verificar a utilização de água da chuva. A segunda Subcategoria - Gestão de Resíduos identifica a) investigar se as cooperativas cumprem as determinações da Lei de resíduos sólidos; b) averiguar a existência de projetos, dentro das cooperativas com o intuito de redução de materiais como copos descartáveis etc. e c) utilizar materiais reciclados e/ou reutilizados para produzir, empacotar produtos e ou prestar serviços (últimos dois exercícios). A terceira Subcategoria - Energia estuda a) analisar a existência na cooperativa de fontes de energia renovável e b) verificar a existência de projetos para redução de desperdício de energia. Além disso, a quarta Subcategoria - Consciência Ambiental pesquisa a) examinar a existência de atuações ambientais durante toda a existência da cooperativa; b) investigar a existência de certificações ambientais; c) averiguar a participação em reuniões e conferências sobre consciência ambiental, responsabilidade ambiental e desenvolvimento sustentável e d) fornecer prêmios de excelência em gestão ambiental.

A dimensão "Social" compreende os condicionantes sociais que visam avaliar o compromisso da cooperativa em buscar melhorar a qualidade de vida, trabalhando com empregados e suas famílias, com a comunidade local e com a sociedade, visando promover a equidade, dando condições melhores de vida a todos, a fim de contribuir com o desenvolvimento econômico sustentável, Esta dimensão possui duas categorias, sendo a primeira Políticas de Gestão de Pessoas que por sua vez é divido em duas subcategorias de análise, sendo uma delas a subcategoria - Relações trabalhistas que busca a)analisar se a cooperativa possui pesquisa de satisfação do empregado; b) verificar o índice de rotatividade do pessoal e c) examinar se a cooperativa tem certificações de boas práticas de higiene Segurança e Saúde no Trabalho da cooperativa. Ainda se tratando das políticas de gestão de pessoas outra subcategoria são os Benefícios aos empregados tendo como foco a) analisar a existência de assistência médica para os colaboradores das cooperativas; b) averiguar a existência de previdência privada para os colaboradores das cooperativas; c) investigar se 
houve acidentes de trabalho e d) proporcionar prêmios de valorização e reconhecimento para os cooperados. A segunda categoria é Comunidade, desmembrada em a) verificar se a cooperativa investe parte do faturamento em projetos sociais, culturais e esportivos para a comunidade e b) analisar se a cooperativa investe parte do faturamento em projetos sociais, culturais e esportivos para a comunidade.

A terceira e última dimensão denominada "Relações Comerciais" compreende os condicionantes que avaliam a capacidade de competitividade das cooperativas e as competências empresariais e de gestão. A dimensão Relações Comerciais tem como foco entender qual é a relação das cooperativas em relação aos seus stakeholders para isso esse indicador foi divido em duas categorias a primeira Marketing e Comunicação e tendo como foco de análise a) verificar a existência de reserva financeira para comunicação de marketing (publicidade, promoção etc); b) examinar a existência ou não da realização de pesquisas de satisfação dos clientes não cooperados e c) pesquisar se a cooperativa possui certificações de qualidade de produtos e serviços. E a segunda Avaliação de Fornecedores e seu foco de análise a) investigar se os fornecedores se preocupam com a qualidade, se eles possuem certificações de qualidade e b) averiguar se os fornecedores da cooperativa possuem características solidárias.

\section{Resultados e Discussões}

\section{1 Área da pesquisa - características do município de Ituiutaba-MG}

Com uma população de aproximadamente 104.526 habitantes, Ituiutaba é um município tradicional situado no Triângulo Mineiro, a cidade é conhecida por sua cultura própria e tradição e estas características, principalmente econômica fazem com que o município seja destaque em múltiplas potencialidades. (MARTINS; SILVA; CASTANHO, 2009).

O serviço Brasileiro de Apoio às Micro e Pequenas Empresas (SEBRAE 2006) revela que a colonização do município aconteceu devido às expedições no interior do Sertão da Farinha Podre atual Triângulo Mineiro. Desde sua colonização o município tem seu fator econômico baseado na agropecuária, apesar de ser caracterizada como uma cidade de pequeno porte tem grande potencial agropecuário o que a torna importante para a Microrregião Geográfica.

\subsection{Avaliação de sustentabilidade de cooperativas agropecuárias no município de Ituiutaba a partir do Sustainability Assessment for Agriculture Cooperatives (SAAC).}

A partir da definição do modelo de análise por meio da utilização do Sistema de Indicadores do modelo Sustainability Assessment for Agriculture Cooperatives (SAAC), foi possível verificar e responder à pergunta da pesquisa se existem práticas de sustentabilidade nas operações de cooperativas agropecuárias no município de Ituiutaba? Elas estão adequadas (atendem) aos indicadores do modelo Sustainability Assessment for Agriculture Cooperatives (SAAC). Os resultados obtidos para Dimensão Ambiental, Social e Relações Comerciais podem ser visualizados nos itens a seguir.

\subsubsection{Dimensão ambiental}

A dimensão ambiental é composta por elementos relativo à categoria gestão ambiental que por sua vez foi subdividido para fins de análise e de avaliação nas categorias "água", "gestão de resíduos", "energia" e "consciência ambiental", os quais foram avaliados positivamente em relação à sustentabilidade, uma vez ambos apresentaram índices cuja classificação é sustentável insustentável. 
A partir das entrevistas realizadas com os colaboradores das cooperativas, notou-se que todas entendem a importância da água e que se trata de um recurso escasso, embora das cinco cooperativas entrevistadas somente três investem em proteção e preservação da água, sendo somente a cooperativa $\mathrm{E}$ que possui um projeto interno do método de captação com drenos das nascentes. As opiniões positivas destacaram a importância da água na garantia da sustentabilidade das operações das cooperativas pesquisadas "é um método pouco utilizado, mas que consegue captar mais água sem que ela se perca no meio" (Entrevistado da cooperativa E).

As cooperativas B e D investem em projetos externos. Como relata o entrevistado da cooperativa B "investimos em projetos externos, pois no atual momento não dispomos de tempo de colocar realmente a mão na massa, por isso optamos por doar determinado valor para uma entidade, que possua ações iguais, queríamos que fosse para nossa cooperativa”.

Na categoria reuso de água as cooperativas de Ituiutaba até o momento não investem, pois justificam que o processo de tratamento para o reuso tem um alto valor que não podem arcar até o momento, os entrevistados, das cooperativas A, B, C ressaltaram a inexistência de processos de tratamento da água em suas cooperativas, dado o elevado custo que impõe a cooperativa "o reuso da água demanda alto valor, pois tem que passar por inúmeros processos de tratamento, fora a construção de uma estrutura que consiga fazer os processos e fazer esta água tratada ir até o destino pretendido", afirma o entrevistado na cooperativa A, "já chegamos a orçar um projeto de reuso, mas para o tamanho da nossa cooperativa o investimento por enquanto não compensaria", revela o entrevistado da cooperativa $\mathrm{B}$. Também foi de interesse avaliar o reuso de água da chuva, deste modo somente a cooperativa E não utiliza da água da chuva, pois defende que "nosso processo de produção é muito cauteloso qualquer coisa estranha geraria grande repercussão, então devido a isso não fazemos este reuso da água da chuva”. Já as outras cooperativas $A, B, C$ e D utilizam da água da chuva, mas para as atividades básicas que não envolvam o processo de produção, "nossa cooperativa entende que a água é um recurso escasso, portanto a água da chuva é visto para nós como um meio de economizar água”, Entrevistado cooperativa D.

A próxima subcategoria que foi analisada neste estudo é a gestão dos resíduos, principalmente ao que tange à nova lei de resíduos sólidos (Lei no ${ }^{12.305 / 10}$ ) que prevê a prevenção e a redução na geração de resíduos, tendo como proposta a prática de hábitos de consumo sustentável e um conjunto de instrumentos para propiciar o aumento da reciclagem e da reutilização dos resíduos sólidos (aquilo que tem valor econômico e pode ser reciclado ou reaproveitado) e a destinação ambientalmente adequada dos rejeitos (aquilo que não pode ser reciclado ou reutilizado).

Ainda na dimensão "Ambiental", a análise da subcategoria "energia" mostrou que somente a cooperativa A dispõe de fontes de energia renovável, uma vez que ela utiliza a energia solar, também foi de interesse saber sobre projetos para reduzir o desperdício de energia e somente as cooperativas A e $\mathrm{C}$ trocaram as lâmpadas incandescentes pelas florescentes e diminuíram a quantidade de lâmpadas no espaço de trabalho a partir de estudo da quantidade necessária de luminosidade para aquele determinado local de trabalho, notou-se falta de conhecimento e interesse das cooperativas entrevistadas em relação à importância da energia, da redução e das opções renováveis A análise relacionada à subcategoria "energia renovável" mostrou que os entrevistados visualizam uma avaliação potencialmente insustentável. Portanto, segundo o entrevistado da cooperativa E "as fontes de energias renováveis, ainda não são uma realidade para nossa empresa, temos ideias de projetos, porém nada saiu do papel”. Já o entrevistado da cooperativa $C$ emendou "nossos mini projetos para redução da energia sabemos que não causam grande impacto, mas é como podemos contribuir no momento e quem sabe em um futuro a implantação de energias renováveis." Para o entrevistado da cooperativa A, a única que revelou dispor de energias renováveis demonstrou estar satisfeito com a implantação da energia solar e ainda revela expandir para a cooperativa toda.

Ainda na avaliação da dimensão ambiental há a subcategoria da consciência ambiental, na entrevista buscou-se identificar se as cooperativas já foram autuadas por infrações ambientais, a 
cooperativa D revelou duas infrações e somente a cooperativa D apresentou uma certificação ambiental a Rainforest Alliance (RFA) - práticas agrícolas corretas. Todas as cooperativas demonstraram buscar por cursos, palestras, congressos para compreender melhor e colocar em prática nas cooperativas e além do aprendizado a busca pelas certificações. No entanto, os dados coletados durante as entrevistas demonstram que as cooperativas tijucanas não praticam a consciência ambiental, visto que um dos pilares que sustentam o cooperativismo é a consciência ambiental, pois possuem forte ligação de identificação e diversas características comuns que devem interagir econômica e socialmente em um mesmo ambiente. (BUTTENBENDER; GIESE, 2015).

Apesar da busca de informações pelas cooperativas, pouco desse conhecimento é transformado em ação, via mobilização de grupos e pessoas na busca por soluções. Portanto, quanto mais forte for à consciência ambiental, maior também será o senso de responsabilidade em relação à preservação dos recursos naturais e da biodiversidade do município, o que aumenta o grau de sustentabilidade que as cooperativas buscam. Percebeu-se, durante as entrevistas, avanços na mudança de comportamento das cooperativas sobre a consciência ambiental, mas ainda são tímidos os debates e as buscas por soluções eficientes, portanto, a consciência ambiental cresce, mas ainda enfrenta desafios.

Como revela o entrevistado da cooperativa B sobre as certificações, "entendemos a importância das certificações, mas realmente o que nos falta são ações que concretizam nosso pensamento". Não somente a empresa B possuiu este pensamento, o gestor da cooperativa A também defende a ideia de que a cooperativa deve ser mais ativa nas ações "tudo fica lindo escrito no papel, mas na hora de fazer que nos deparamos com os problemas e dificuldades, principalmente quando alguma ação requer dinheiro".

O gestor da cooperativa $\mathrm{D}$, durante a entrevista, fala "temos um grande problema em nossa cooperativa, apesar das participações em palestras, treinamento e enfim, não conseguimos fazer com que este conhecimento transmitido traga resultados para a empresa, acreditamos que existe um abismo e estamos buscando entender o porquê disso acontecer, pois de certa forma estamos jogando dinheiro fora, que era na verdade um investimento para a cooperativa."

\subsubsection{Dimensão social}

A dimensão social compreende os condicionantes sociais que visam avaliar o compromisso da cooperativa em buscar melhorar a qualidade de vida, trabalhando com empregados e suas famílias, com a comunidade local e com a sociedade, visando promover a equidade, a fim de dar melhores condições de vida a todos, contribuindo assim, com o desenvolvimento econômico sustentável dividido em subcategorias como "relações trabalhistas" e "benefícios aos empregados", também a dimensão social engloba como a cooperativa impacta na comunidade ao seu redor.

Diante desta dimensão, analisaram-se os colaboradores das cooperativas e mensuram o nível de satisfação de seus colaboradores, Desse modo, foi revelado que as cinco cooperativas pesquisadas não apresentam nenhum método que se refira à satisfação de seus empregados, "mas temos uma caixa de sugestão oule elogios, até mesmo para o colaborador se sentir à vontade em falar sem se expor" revela o entrevistado da cooperativa E, já o entrevistado da cooperativa A afirma "realmente não temos um método que mensure a satisfação, mas construímos um ambiente aberto para até mesmo os colaboradores se sentirem a vontade para conversar sobre assuntos pertinentes ao ambiente de trabalho".

Desse modo, também foi analisado o índice de rotatividade nas cinco cooperativas e as entrevistas mostraram que o índice de rotatividade é baixo, as cooperativas não revelaram números, mas o entrevistado da cooperativa B explica o motivo "nos preocupamos muito com nossos colaboradores, não os vemos como números, mas sim como pessoas que possuem famílias. 
Em meio à crise, evitamos fazer demissões e buscamos cortar os custos, acredito que essa nossa preocupação reflete nos colaboradores e consequentemente o índice baixo de rotatividade”.

Ainda se tratando do ambiente interno da empresa e focado nos colaboradores, buscaram-se as certificações de boas práticas de higiene, segurança e saúde no trabalho, contudo as cinco cooperativas revelaram possuir tais certificações, "vemos estas certificações de higiene e principalmente segurança e saúde no trabalho como uma obrigação para nossa cooperativa, pois acredita-se que isso torna o trabalho do dia a dia mais prazeroso e confiável" afirma o entrevistado da cooperativa D, "um ambiente que encontramos estas três palavras higiene, segurança e saúde, já temos a visão que se preocupa com seus colaboradores e esta é a imagem que buscamos e queremos passar para as pessoas" assim revelou o entrevistado da cooperativa B. A próxima subcategoria da dimensão social avaliada foi à questão dos "benefícios aos empregados", as cooperativas A, B e C não possuem plano de saúde, somente as cooperativas D e E oferecem planos de saúde aos seus funcionários. Outro beneficio levantado na entrevista foi à previdência privada que todas cooperativas disseram conceder aos seus funcionários, visto que a existência da previdência privada está prevista na própria Constituição Federal de 1988, art. 202, que basicamente é organizada de forma autônoma, as empresas escolhem se optam ou não a pagar para seus funcionários.

Constatou-se na dimensão social que somente a cooperativa D apresentou um acidente de trabalho e ainda falou que ele foi durante o percurso de ida a cooperativa para o serviço diário.

Explorou-se também se as cooperativas possuem ações que valorizam e reconhecem o colaborador, as cooperativas B, C e E possuem estes objetivos com ações diferentes, sendo que a cooperativa B realiza eventos todos os anos, homenageando os colaboradores com dez e cinco anos na empresa, já a cooperativa $C$ revelou que sua forma de valorizar o colaborador é dar feedbacks positivos na frente dos colegas de trabalho que ainda defendeu ser uma forma de motivação e a cooperativa $\mathrm{E}$ faz todo trimestre um painel para homenagear o colaborador com melhor desempenho e isso é feito por meio das votações dos funcionários da cooperativa. Já as cooperativas A e D responderam não fazer ações, mas possuem projetos futuros de implementação que não revelaram durante a entrevista. Alguns excertos das entrevistas são reveladores neste sentido "homenagear nossos colaboradores nos dá uma sensação que nos importamos e sabemos da carreira e tempo de cada um na empresa e isso motiva" disse o entrevistado da cooperativa B, "o reconhecimento trimestral que é realizado é necessário, pois conseguimos fazer que toda cooperativa se envolva e mostra que qualquer um independente da posição que ocupa na cooperativa pode ser reconhecido", revela o gestor da cooperativa E.

Finalizou-se a avaliação da dimensão social na sustentabilidade das cooperativas explorando a parte social um dos pilares que as fazem transformadoras, constatou-se que as cooperativas agropecuárias de Ituiutaba/MG investem em projetos sociais, culturais e esportivos para a levando conhecimento sobre a agropecuária tanto para os alunos e pais, já as cooperativas B e D realizam palestras para a comunidade e os cooperados sobre finanças pessoais e investem em projetos realizados por terceiros assim como a cooperativa $C$.

\subsubsection{Dimensão relações comerciais}

A dimensão das relações comerciais engloba duas categorias, sendo a primeira "marketing e comunicação" explora essa temática por meio de três perguntas a serem identificadas e reveladas durante as entrevistas nas cooperativas, já a segunda categoria é des membrada em duas perguntas que analisam a "avaliação dos fornecedores".

A percepção geral dos entrevistados é de que as cooperativas não investem em propagandas que exigem um alto valor a ser aplicado, apenas a cooperativa B possui site a quem paga uma empresa terceirizada para fazer a gestão, as outras cooperativas declararam apenas possuir e-mails que divulgam seus trabalhos e onde se encontram a maioria do público alvo. 
O principal reflexo negativo identificado pelos entrevistados nesta dimensão foi a ausência da realização da pesquisa de satisfação dos clientes diante da importância deste artigo para o bom funcionamento organizacional. Os excertos das entrevistas são claros neste sentido, pois "não fazemos pesquisa de satisfação dos clientes, pois acreditamos ter um ambiente aberto entre nosso cliente e empresa e temos clientes de anos o que nos faz acreditar que nosso serviço é ótimo, mas sempre buscamos melhorar", fala o gestor da cooperativa B, já o gestor da cooperativa E argumenta "realmente ter uma ferramenta que realiza a pesquisa de satisfação dos clientes é um meio para melhorarmos nossos produtos e serviços, pois quem está dentro da cooperativa talvez não tenha uma mesma visão de quem está de fora", o gestor da cooperativa $C$ revela "já chegamos a implantar um método que após o atendimento ao cliente recebia um e-mail de avaliação, mas o retorno das respostas era baixo, então optamos por não fazer mais, mas estamos avaliando a possibilidade de uma nova forma de avaliar, pois acreditamos no poder dos resultados das pesquisas de satisfação".

Dados revelam que apenas duas cooperativas declararam possuir certificações de qualidade ISO 9000 e ambiental ISO 14001, as quais certificam a qualidade nos processos e um desempenho ambiental correto das cooperativas. As outras cooperativas $\mathrm{C}$, D e E revelaram não possuir certificações, mas estão em busca da adequação para conquistá-las, o que se evidencia a um caminho ainda incipiente para o alcance da sustentabilidade em operações das cooperativas pesquisadas.

Por fim, na categoria "avaliação de fornecedores", buscou-se identificar nas entrevistas se as cooperativas se preocupam com as certificações de qualidade e se existe algum critério para se tornar fornecedor. Todas cooperativas declaram se preocupar com as certificações, mas o foco como observado nas entrevistas era em relação ao preço e a agilidade de entrega e todas também destacaram que se importam com as características solidárias de seus fornecedores, não há como negar, entretanto, que não é um critério que julgam na hora da contratação. Alguns trechos das entrevistas revelam esse entendimento "o primeiro passo para contratarmos um fornecedor é através da comparação de preços e em segundo lugar com a agilidade de entrega e claro sempre pesquisamos sobre as certificações e recomendações de nossos fornecedores" mostra o gestor da cooperativa A, já o gestor da cooperativa E argumenta "sempre buscamos fornecedores que cumpram as leis, mas também nos preocupamos bastante com o preço", o gestor da cooperativa B revela também "preço é primordial na escolha e as ações solidárias vemos como um diferencial que pode ou não pontuar na escolha do fornecedor".

\section{Conclusões}

Diante dos resultados expostos anteriormente, propôs-se avaliar a sustentabilidade nas operações de cooperativas agropecuárias no município de Ituiutaba em Minas Gerais a partir da aplicação do modelo de avaliação de sustentabilidade denominado Sustainability Assessment for Agriculture Cooperatives (SAAC). Essa avaliação possibilitou uma visão ampla dos principais aspectos sociais e ambientais que favorecem as sustentabilidades das operações das cooperativas agropecuárias do município de Ituiutaba - MG.

Com os resultados obtidos até aqui, pode-se inferir que as operações de produção das cooperativas agropecuárias no município de Ituiutaba/MG são insustentáveis. Das cinco cooperativas estudadas, apenas uma apresentou condições excelentes para a sustentabilidade, destacando-se em relação a todo o conjunto. Portanto, os resultados encontrados com a col eta de dados remetem para o baixo nível de sustentabilidade nas operações das cooperativas agropecuárias do município de Ituiutaba/MG.

Consideram-se preocupante os problemas relacionados ao não uso de fontes de energias renováveis pelas cooperativas pesquisadas, além do deficit no reuso da de água na zona rural. 
Este artigo possibilitou, portanto, a exposição de uma espécie de diagnóstico situacional que retrata as condições de como são desenvolvidas as atividades no setor agropecuário tijucano, uma vez que as categorias no SAAC demandam mais atenção, e que categorias analisadas apresentaram uma baixa sustentabilidade e performance e as implicações para o município. Assim, percebeu-se que apesar de esforços das cooperativas no caminho da sustentabilidade, existem falhas ou omissões na efetivação dos critérios de sustentabilidade nas ações e operações das cooperativas agropecuárias no município de Ituiutaba/MG.

Uma barreira quanto à sustentabilidade evidenciada na fase de análise dos dados foi a não efetivação da prática da educação cooperativista de forma perene nas cooperativas, mas ações isoladas neste sentido. Essa dificuldade evidenciou-se tanto pela falta de habilidades e pelo treinamento de cooperados e terceirizados para a educação cooperativista no setor de cooperativas agropecuárias no município (SAFANELLI, 2011).

A análise dos dados desta monografia mostrou, ainda, que as cooperativas ressentem em não se adaptar ao plano nacional de resíduos sólidos que poderia transformar as operações das cooperativas em uma política de sustentabilidade efetivamente disseminada em todas as cooperativas agropecuárias do município a fim de influenciar de modo significativo na governança ambiental.

A não existência efetiva da consciência ambiental disseminada, como a deficiência de projetos sociais que atendem à comunidade, baixo reuso da água e incipiente uso de energias renováveis, a não implementação efetiva de um padrão de interoperabilidade sustentável capaz de permear toda a estrutura das cooperativas pesquisadas foram vistas como barreiras para a sustentabilidade das operações das cooperativas agropecuárias tijucanas. Dessa forma, ante as opiniões dos entrevistados, o estágio atual da sustentabilidade das operações das cooperativas no município foi visto como incipiente, refletindo, em boa parte dos casos, a impressão que se teve sobre a maturidade de algumas categorias analisadas do modelo na ação efetiva das cooperativas pesquisadas. Portanto, o estágio atual da sustentabilidade das operações de cooperativas agropecuárias no município de Ituiutaba/MG estar num patamar desfavorável. Assim, o município é visto como não estando "bem colocado" no esforço de tornarem suas operações mais sustentáveis, impressão de que é alavancada por diversos entrevistados. Portanto, a incorporação dos critérios de sustentabilidade nas cooperativas pode contribuir com um dos grandes objetivos das cooperativas agropecuárias de forma geral, qual seja, "atuam no fomento e na comercialização dos produtos agrícolas, inclusive, implantando novos cultivos e agregando valor aos produtos por meio de complexos agroindustriais sustentáveis" (GIMENES; GIMENES, 2006, p. 389). Na prática, entretanto, os ganhos em eficiência, eficácia e efetividade dependeriam criticamente da sustentabilidade organizacional.

Por fim, as conclusões apresentadas nesta subseção, sobre a sustentabilidade das operações das cooperativas tijucanas podem mostrar novos caminhos para o emprego do modelo SAAC, visto que ela ainda não explorou devidamente a sua aplicação em outras cooperativas de outros municípios do Triângulo Mineiro em suas contribuições.

\section{Referências}

ABARGHANI, M. E.; SHOBEIRI, S. M.; MEIBOUDI, H. Implementation of a rural cooperative management for achieve sustainable development for the first time in Iran. Advances in Environmental Biology, v. 7, n., p. 1937-1941, 2013.

AKTOUF, O. Pós-globalização, Administração e Racionalidade Econômica: A síndrome de avestruz. Ed. Atlas, 2004.

ALMEIDA, H. M. M. Autogestão: da ideia as praticas. Revista de Administração de Empresas. Rio de Janeiro, v. 23, n.1, p. 37-57, jan\mar, 2006. 
ALVARES, G. R.; COSTA, I. F. Os impactos do acidente de trabalho. Acadêmicos do $8^{\circ}$ período do Curso de Ciências Contábeis da Faculdade Presidente Antônio Carlos FUPAC Ubá - MG.2015. Disponível:www.webartigos.com/storage/app/uploads/public/588/508/229/58850822 9b3e5486118382.pdf. Acesso em o7 de out. 2018.

BENATO, J. V. A. O ABC do cooperativismo. Organização das Cooperativas do Estado de São Paulo 2 ed., 1994

BORGES, F. Q.; ZOUAIN, D. M. A matriz elétrica no estado do Pará e seu posicionamento na Promoção do desenvolvimento sustentável. Planejamento e políticas públicas, v. 2, n. 35, 2011.

BUTTENBENDER, P. L.; GIESE, E. Gestão da sustentabilidade ambiental no cooperativismo: O caso da Cooperativa Mista São Luiz Ltda - Coopermil. 2015. Disponível em:http://bibliodigital.unijui.edu.br:8o8o/xmlui/bitstream/handle/123456789/2904/Artigo\% 2ofinal\%2orevisado\%2opdf.pdf?sequence=1. Acesso em: o1 de Out. 2018.

DELAI, I.; TAKAHASHI, S. Sustainability measurement system: A reference model proposal. Social Responsibility Journal, v. 7, n.3: 2011, p.438-471

DATACOPER. Cooperativas agrícolas: o que são e como funcionam?. 2018. Disponível em: http://blog.datacoper.com.br/cooperativas-agricolas-o-que-sao-e-como-funcionam. Acesso em: 17 de Jul. 2018.

DAVIES, F. Sistema contábil gerencial ambiental: índice de sustentabilidade em uma propriedade rural. Trabalho de Conclusão de Curso, Universidade Regional do Noroeste do Estado o Rio Grande o Sul 2017

DOMENICO, D. D. et al. Análise de Sustentabilidade Ambiental: Estudo de Caso em Uma Indústria de Eletrodomésticos. ConTexto, Porto Alegre, v. 15, n. 31, p. 24-37, set./dez. 2015.

FRANTZ, W. Educação para o cooperativismo: a experiência do movimento comunitário de base de Ijuí. In: Educação cooperativa e suas práticas. Org SCHNEIDER, J.O. Brasilia: SESCOOP, 2003.

GIMENES, Régio Márcio Toesca; GIMENES, Fátima Maria Pegorini. Cooperativismo Agropecuário Os Desafios do Financiamento das Necessidades Líquidas de Capital de Giro. Revista Economia contemporânea, v.10, n.2, p.389-410, Rio de Janeiro, mai./ago. 2006.

HUBERMAN, L. História da riqueza do homem. [S.I]: Zahar Editores, 1981.

INSTITUTO BRASILEIRO DE GEOGRAFIA E ESTATISTICA - IBEGE. Secretaria de Planejamento e Coordenações da Presidência da Republica. Boletim de serviços. Rio de Janeiro, Suplemento 1763, semanas 927 a 931. p. 2, ano XXXVIII, 1989.

KLEINDORFER, P.; SINGHAL, K.; VAN WASSENHOVE, L. Sustainable Operations Management. Production and Operations Management, v. 14, n. 4, p. 482- 492, 2005.

KLAES, L. S. Cooperativismo e ensino à distância. Tese de Doutorado, Universidade Federal de Santa Catarina, Centro Tecnológico. Programa de Pós-Graduação em Engenharia de Produção, 2005.

MARCIS, J. Proposta de modelo de avaliação do desempenho em sustentabilidade das operações de cooperativas agropecuárias.

em:file:///C:/Users/debora/Downloads/Modelo\%2ode\%2oAvalia\%C3\%A7\%C3\%A30\%2oS

AAC\%2ode\%2oCooperativas.pdf. Acesso em: 29 de jun. 2018.

MARTINS, D. D.; SILVA, R. L. G.; CASTANHO, R. B. ITUIUTABA - MINAS GERAIS/BRASIL: sua organização sócio-espacial analisada com o suporte do Geo processamento. Disponível em: observatoriogeograficoamericalatina.org.mx/egalı2/Nuevastecnologias/Sig/11.pdf

NEVES, M. C. R. Avaliação do desempenho das cooperativas participantes do programa de capitalização de cooperativas agropecuárias (PROCAP-AGRO). Disponivel em: www.locus.ufv.br/bitstream/handle/123456789/66/texto\%2ocompleto.pdf?sequenc e=1. Acesso em: 29 de Jun. 2018. 
NUNES, D. Incubação de empreendimentos de economia solidária: Uma aplicação da pedagogia da participação. 1. Ed. São Paulo: Annablume, 2009.

OAKLAND, J. S.; OAKLAND, S. The links between people management, customer satisfaction and business results. Total Quality Management, v9, n.4-5, p.185-190, 1998.

OLIVEIRA JR. C. Avaliação da eficiência empresarial das cooperativas. Ocepar, 1996. ORGANIZAÇÃO DE COOPERATIVAS BRASILEIRAS - OCB. OCB divulga panorama do cooperativismo brasileiro em 2012. Disponível em: www.ocb.org.br/site/agencia_noticias/noticias_detalhes.asp?CodNoticia=13837.. Acesso em: Acesso em: 29 de Jun. 2018.

PORTIL, R. M. PEIXE, B. J. Avaliação da eficiência das cooperativas agroindustriais paranaenses: uma abordagem econômica e social utilizando DEA. XLVI Congresso da Sociedade Brasileira de Economia, Administração e Sociologia Rural Rio Branco - Acre, 20 a 23 de jul. 2008.

PORTO, W. S. avaliação de desempenho de cooperativas de crédito rural baseada no uso do balanced scorecard: uma proposta de modelo. Disponível em: repositorio.ufsc.br/xmlui/bitstream/handle/123456789/82466/190483.pdf? sequence $=1 \&$ isAllowed $=\mathrm{y}$. Acesso em: 05. jul. 2018.

RAJA, I. L.; N. LEMA, D. La eficiência técnica como medida de rendimiento de las cooperativas agrárias. CIRIEC-Espanha, Revista de Economía Pública, Social y Cooperativa, n. 55, agosto 2006, p. 289-311.

REISDORFER, V. K. Introdução ao cooperativismo. Santa Maria: Universidade Federal de Santa Maria, colégio Politécnico, rede e - Tec Brasil, 2014.

RIOS, G. S. L. O que é cooperativismo. Editora Brasiliense, $1^{\underline{a}}$ edição ebook, 2018.

ROSA, P. E. Políticas públicas de economia solidária no Rio Grande do Sul. RURAL NEWS. A Importância das Cooperativas Agropecuárias. Disponível em: www.ruralnews.com.br/visualiza.php?id=780. Acesso em: 17 de jul. 2018.

SAFANELLI,Arcângelo Dos Santos et al. Educação Cooperativa: Valorização do Ser Humano. XI Colóquio Internacional Sobre a Gestão Universitariano Brasil, Florianópolis. 7 a 9 de dezembro de 2011.

SALES, J. E. Cooperativismo: Origens e Evolução. Revista Brasileira de Gestão e Engenharia, n.1, Janjun 2010 .

SÁNCHEZ, A. MARTÍ, E. La medición del desempeño de las sociedades cooperativas agrárias. Perpectiva de los directores-gerentes de las provincias de Huelva y Jaén. CIRIEC- Espanha, Revista de Economía Pública, Social y Cooperativa, n. 46, noviembre 2003, p. 85- 116.

SERVIÇO BRASILEIRO DE APOIO ÀS MICRO E PEQUENAS EMPRESAS - SEBRAE,Circuito Turístico Águas do Cerrado - Diagnóstico. Belo Horizonte, 2006. 191 p.

SICOOB. Os diferentes tipos de cooperativas. 2016. Disponível em: www.oseudinheirovalemais.com.br/os-diferentes-tipos-de-cooperativas/. Acesso em: 17 de Jul. 2018.

SOUTO, S. T.; BEZZI, M. L. A produção do leite bovino em Ituiutaba-MG: Uma analise da dinâmica produtiva e da influencia para o desenvolvimento local. XII seminário internacional sobre desenvolvimento regional. Territórios, redes e desenvolvimento regional: perspectivas e desafios. Santa Cruz do Sul, RS, Brasil, 13 a 15 de setembro de 2017.

TINOCO, J. E. P.; ROBLES, L. T. A contabilidade da gestão ambiental e sua dimensão para a transparência empresarial: estudo de caso de quatro empresas brasileiras com atuação global. Rap. Nov. /Dez. 2006. Disponível em: www.scielo.br/pdf/rap/v4on8/o8.pdf. Acesso em: 26 jul. 2019 
37 | Aplicação do modelo sustainability assessment...

ZYLBERSZTAJN, D. Quatro estratégias fundamentais para as cooperativas agrícolas. IN: BRAGA, M.J., REIS, B.S. (Org.). Agronegócio cooperativo: reestruturação e estratégias. Viçosa: UFV, 2002. P. $55-75$. 